\title{
Humildad y Grandeza pueden combinarse: el ejemplo de los doctores José Félix Patiño Restrepo y Stanley J. Dudrick
}

\author{
Humility and Greatness can be combined: the example of doctors \\ José Félix Patiño Restrepo and Stanley J. Dudrick \\ Humildade e Grandeza podem ser combinadas: o exemplo dos médicos \\ José Félix Patiño Restrepo e Stanley J. Dudrick \\ Humberto Arenas Márquez, MD, FACS-FASPEN ${ }^{*}$
}

Recibido: 4 de abril de 2020. Aceptado para publicación: 5 de mayo de 2020

Publicado en línea: 14 de mayo de 2020

https://doi.org/10.35454/rncm.v3n2.156

La Nutrición Clínica Latinoamericana está de luto. Hemos perdido a dos gigantes de la Nutrición Clínica, el Dr. Stanley Dudrick reconocido como el Padre de la Nutrición Intravenosa y fallecido el 18 de enero de 2020, y también su gran amigo el Dr. José Felix Patiño Restrepo pionero de la Nutrición Intravenosa en Colombia fallecido el 26 de febrero del 2020. Había tanta identificación y coincidencia entre ambos que volaron prácticamente juntos al cielo donde sin duda están ahora gozando de la eternidad.

En vida recibieron múltiples reconocimientos por sus logros científicos y académicos, por ello me referiré tan solo a su perfil humano y especialmente a la última etapa de su vida de la cual todos los profesionales de la salud que tuvimos el privilegio de conocer y especialmente los médicos pudimos aprender de sus lecciones.

A lo largo de su vida, los doctores Dudrick y Patiño impartieron sabiduría, compartieron sus conocimientos y habilidades con todo aquel colega que tocase a su puerta, desarrollaron talentos y fueron modelos en valores sociales, personales y profesionales; por ello han trascendido en nosotros como mentores y somos nosotros los herederos de sus legados ${ }^{(1)}$.

Unidad de Práctica Integrada en Falla Intestinal del Hospital San Javier Guadalajara, México.

${ }^{*}$ Correspondencia: Humberto Arenas M. arenas50@hotmail.com
Por otro lado, nuestros Colegas crecieron y se desarrollaron en proporción directa a los retos que enfrentaron con coraje, dignidad y una férrea voluntad para salvaguardar la vida de sus pacientes, defendiendo sus ideales, demostrándonos que siempre se puede hacer algo por los demás, siempre se pueden tener nuevas ideas y así se convirtieron en modelos a seguir.

Pero lo más sorprendente es que nos demostraron la forma de hacer y cultivar relaciones amorosas y de respeto con todos aquellos que les rodeaban. De sus conexiones con la gente obtenían su fuerza vital y especialmente su amistad con gente joven les proporcionaba alegría, en esa relación daban más de lo que recibían, compartiendo su experiencia de vida y en ese acto sublime de contribuir al aprendizaje y al bienestar de los demás aumentaba su nivel de confianza, aprecio y franqueza y de esa manera transmitían una reconfortante sensación de seguridad $\mathrm{y}$ tranquilidad.

Ambos utilizaron al máximo su carisma, su inteligencia y su esfuerzo para ir construyendo su imperio de influencia, atrayendo con su liderazgo a talentosos profesionales y mediante la confianza y la compasión se fortalecieron para ser más resilientes a la hora de enfrentar dificultades teniendo la capacidad de transformarlas en condiciones más positivas.

Finalmente me referiré a las últimas etapas de sus vidas pues pudimos gozar a ambos en su senectud y ahí es donde nos demostraron su humildad y su grandeza. La humidad descrita como la virtud que está en el centro de nuestra espiritualidad. 
Sin duda la humildad que encontramos en los Colegas Dudrick y Patiño les permitió tener una vida profesional y personal más plena y fructífera.

Aceptaron su grandeza, ese estado emocional que nos permite reconocernos, a nosotros mismos y a otros, con el más alto nivel de estimación posible. Su grandeza está en su "forma de ser" y fue adquirida y demostrada a través de acciones ejemplares.

$\mathrm{Al}$ aceptar su grandeza, asumieron no solo sus propias virtudes y aptitudes, sino también las que en los demás merecen reconocimiento ${ }^{(2)}$.

¿Se puede aceptar la grandeza y ser humilde? Sin duda los doctores Patiño y Dudrick demostraron que ambas son complementarias si se usan adecuadamente porque nos permite reconocer nuestros valores y las virtudes de otros y en tal forma hacer una completa apreciación de nuestro compromiso de vida y el de nuestros semejantes.

El aceptar la grandeza está basado en un entendimiento de los seres humanos, en cuidarlos con interés especial, aceptando y tolerando a otros, así como aceptarnos a nosotros mismos. La grandeza les dio vida al proveerles auto-respeto.

Aceptar su grandeza les llevó más cerca de reconocer la humildad como una fuerza importante detrás de su conducta humana y de su actitud profesional.

Así pues llevaron un estilo de vida resiliente. Conseguirla fue un proceso de toda una vida que implicó una evaluación constante y sincera de sus puntos fuertes y débiles, de sus objetivos y expectativas, de realizar actividades basadas en sus valores que les proporcionaban satisfacción y alegría (Figuras 1 y 2).

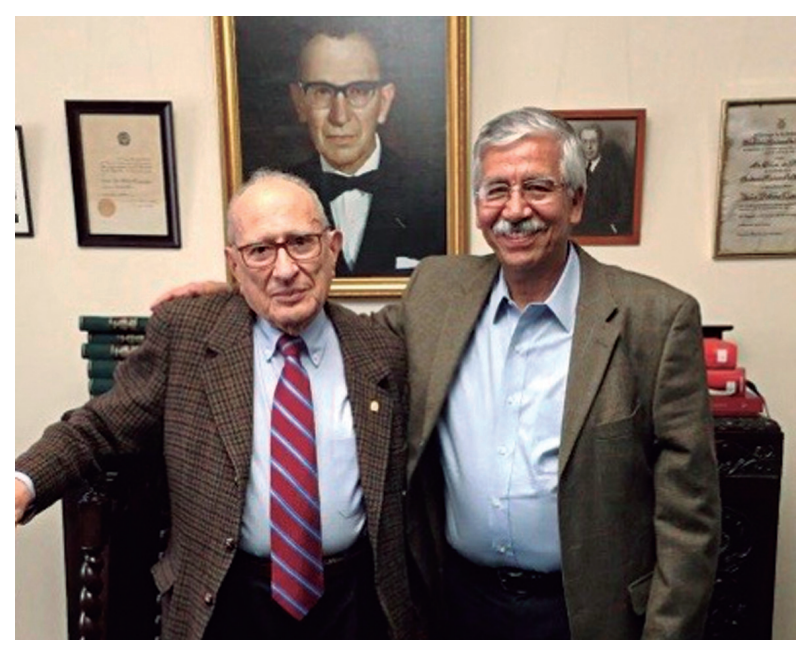

Figura 1. Los doctores José Félix Patiño Restrepo y Humberto Arenas Márquez en la Academia Nacional de Medicina, Bogotá, D.C, Colombia, 2018.

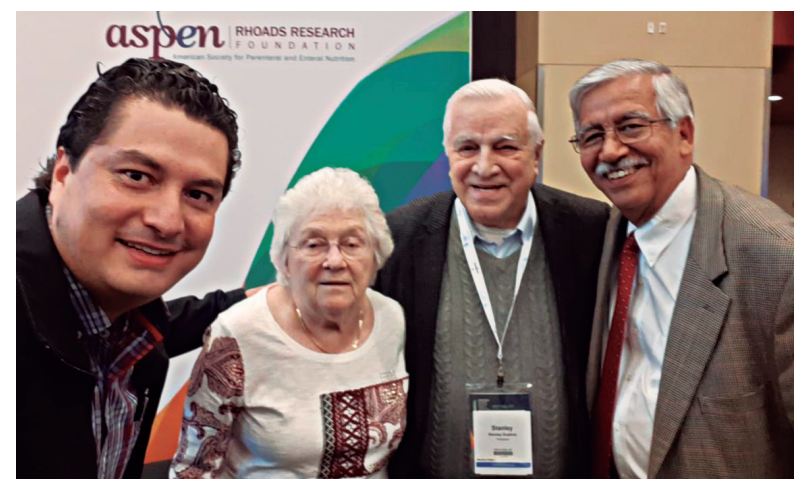

Figura 2. Los doctores Diego Arenas Moya, Humberto Arenas Márquez, Stanley J. Dudrick y su esposa en el congreso de ASPEN en Phoenix, USA en 2019.

Cada uno supo soportar su propia carga, sus pasos lentos apoyados por un bastón o el brazo de la familia o el amigo que siempre estaba dispuesto a hacerlo y así sentir el privilegio de acompañar esos pasos donde iban dejando huella al transmitir energía vital, paz interior y sabias palabras donde ellos no meditaban sobre la muerte sino sobre la vida.

Los hombres buenos como los doctores José Félix Patiño Restrepo y Stanley J. Dudrick viven y nunca se desvanecen; ellos vivirán siempre por los años venideros. ¿Seremos capaces de imitarlos e incluso superarlos como ellos hubieran querido? La decisión apreciado Colega está en tu "forma de ser".

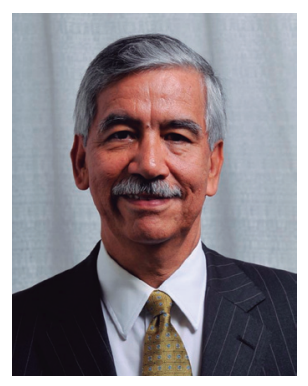

El doctor Humberto Arenas Márquez nacido en Guadalajara México, es médico egresado de la Facultad de Medicina de la Universidad de Guadalajara en 1973. Tiene un posgrado de cirugía general del hospital de especialidades IMSS. Es expresidente de la FELANPE, de la Asociación Mexicana de Alimentación Enteral y Endovenosa (AMAEE), expresidente de la Asociación Mexicana de Cirugía General, Miembro honorario de la Asociación Mexicana de Cirugía General, miembro emérito de la Academia Mexicana de Cirugía. Actualmente es el director de la Unidad de Práctica Integrada en Falla Intestinal del Hospital San Javier en Guadalajara, México.

\section{Referencias bibliográficas}

1. Economopoulos KP, Sun R, Garvey E, Hogan J, Bazzarelli A. Coaching and Mentoring modern surgeons. Bull ACS. 2014;99:30-5.

2. Toledo Pereyra LH. Aceptando la grandeza. En: Toledo Pereyra LH. Innovación y Descubrimientos en Cirugía, Historia y Entorno Humanístico. Coyoacán, México: Asociación Mexicana de Cirugía General; 2013. pp. 130-4. 